\title{
UMA TRADUÇÃO DE AMERS DE SAINT-JOHN PERSE
}

\section{Bruno Palma}

Às dificuldades inerentes a toda tradução poética, vêm juntar-se as peculiares à tradução da poesia de Saint-John Perse. Essa empresa não é impossível, como ele próprio afirmava, mas há que levar em conta as exigências que o texto persiano apresenta e que Perse explicitou por ocasião das traduções de obras suas para o inglês, nas quais tomou parte ativa, para alegria e desespero dos seus tradutores.

E é a leitura dos textos em que se consignaram as dificuldades dos tradutores e as observações e correções do poeta, analisados por Shlomo Elbaz (1977) e Henriette Levillain (1987), que nos farão compreender o que Saint-John Perse pede a quem se proponha vertê-lo para um outro idioma.

Destacamos duas exigências do texto persiano que solicitam maior atenção:

1. o respeito à ordem direta das palavras na frase; e

2. o respeito aos sons e sua relação com o sentido.

Embora metrificada, ainda que de forma peculiar, a poesia de Perse não suporta inversões na ordem das palavras, nem enjambements ou outros recursos que a poesia de outros poetas oferece ao tradutor. Assim sendo, buscamos "colar-nos" ao texto original, de ouvido bem atento à sua musicalidade, levando em conta o ritmo da frase, sem descurar, em momento algum, da sua métrica “interna”. E ritmo, aqui, não se refere só ao ritmo musical, mas também àquele no plano da sintaxe e da semântica, e não só da frase, mas dos períodos maiores, como as seqüências, os cantos, o poema todo.

E já passamos para a segunda exigência: a atenção à complexa mas fundamental relação som/sentido. Da boa solução dos problemas colocados nesse ponto central da poesia, depende a solução de muitos outros. Valéry (apud Elbaz, 1977: 169 n. 15) disse que o poema é uma "hesitação prolongada entre som e sentido" ("Le poème - cette hésitation prolongée entre le son et le sens"). Contudo, é preciso entender bem que, na 
poesia de Saint-John Perse, em princípio, o primado deve ser dado ao sentido. ${ }^{1}$

Porém, se é verdade que "jamais um som pode, por si mesmo, significar alguma coisa," " sem embargo, o uso freqüente de certos fonemas ou combinações de fonemas por Saint-John Perse faz parte essencial do seu projeto poético: imitar o real. ${ }^{3}$ E, como o tema principal de Amers é o mar, reproduzir a música do mar, como o movimento das ondas e o fervilhar da espuma. E a tradução deve levar isso em conta.

Para ilustrar o que dissemos, damos em seguida alguns exemplos:

\author{
1. Invocação 6 - No longo versículo que começa com as palavras "La Mer \\ mouvante et qui chemine", destaca-se a aliteração em $m$ :
}

La Mer mouvante et qui chemine au glissement de ses grands muscles errants, la Mer gluante au glissement de plèvre, et toute à son afflux de mer, s'en vint à nous sur ses anneaux de python noir,

Très grande chose en marche vers le soir et vers la transgression divine...

— que ficou assim:

O Mar movente e que caminha no deslizamento dos seus grandes músculos errantes, o Mar viscoso de um deslizamento de pleura, e todo em seu afluxo de mar, veio a nós em seus anéis de píton negro,

Grandíssima coisa em marcha para a tarde e para a transgressão divina...

Entretanto, as combinações de $l, s$ e outras consoantes -

\footnotetext{
${ }^{1}$ Em principio se deve dar a primazia ao sentido e não ao som. Mas o próprio poeta, quando desejava mudar uma palavra no seu texto, ao corrigi-lo, ou quando de uma nova edição de obra sua, escolhia uma outra levado não tanto por um significado idêntico, mas pelo número de sílabas e aspecto fônico semelhante.

${ }^{2}$ Madeleine Frédéric (1978: 130 segs.), falando na "função imitativa", cita Paul Debrouille (1961: 21): "É preciso lembrar-se que "os sons e o material formal, em geral, estão sempre à disposição do sentido, mas que JAMAIS UM SOM PODE POR SI SÓ SIGNIFICAR ALGUMA COISA. É patente, ao contrário, que em todos os casos de efeitos produzidos pelo som, este último só desempenha uma função a partir do sentido, como um elemento secundário. [...] As possibilidades imitativas dos sons da linguagem dependem, antes de tudo, do sentido, na medida em que é ele que nos põe no caminho". E Frédéric arremata: "Assim, o papel desempenhado por um fonema em tal passagem não será necessariamente o mesmo que ele desempenhará numa outra". Contudo, temos que matizar essa opinião. E é isso que faz o poeta e tradutor Octavio Paz. Segundo ele, o ritmo já é, por si mesmo, significante: "El ritmo es inseparable de la frase; no está hecho de palabras sueltas, ni es solo medida o cantidad silábica, acentos y pausas; es imagen y sentido. Ritmo, imagen y sentido se dan simultáneamente en una unidad indivisible y compacta: la frase poética, el verso" (Paz 1956: 70).

${ }^{3}$ SJP, em várias ocasiões, explicita o que ele chama de "lei de equivalência, em poesia, entre a linguagem e o real", afirmando que "[a] função do poema [...] é de tornar-se, de viver e de ser a própria coisa [...] e não mais o tema, anterior ao poema" (Carta a Luc-André Marcel, de 1.11.1959, Perse 1994: $573)$.
} 
— imitando o fluxo fervilhante das águas do mar, nem sempre são fáceis de transpor. Contudo, a pronúncia, em português, dos $s$, dos $z$ e do $x$ como $k s$, dá um efeito semelhante:

deSLiZamento | múSCuLoS | viScoSo | deSLiZamento | Pleura | aFLuXo

2. Idem - No versículo que começa com as palavras "Et de plus haut, et de plus haut déjà", que vai até "la nuit sans tain des choses", temos uma aliteração em $l$. Pudemos guardar alguns desses fonemas na tradução, ou compensamos, usando outras palavras em que eles figuram: notre escient,

... Et de plus haut, et de plus haut déjà, n'avions-nous vu la Mer plus haute à

Face lavée d'oubli dans l'effacement des signes, pierre affranchie pour nous de son relief et de son grain? - et de plus haut encore et de plus loin, la Mer plus haute et plus lointaine... inallusive et pure de tout chiffre, la tendre page lumineuse contre la nuit sans tain des choses?...

Em português ficou assim: cientemente,

... E de mais alto, e de mais alto já, não víramos o Mar mais alto

Face lavada de olvido na abolição dos signos, pedra livrada para nós do seu relevo e do seu grão? - e de mais alto ainda e de mais longe, o Mar mais alto e mais longínquo... inalusivo e puro de toda cifra, a tenra página luminosa contra a noite cristalina das coisas?...

\section{Estrofe IV}

Nos livres lus, nos songes clos, n'était-ce que cela?

A seqüência [y]-[õ]-[a], pela progressiva abertura das vogais, parece sugerir a saída de uma situação. Porém, levando em conta o que se segue: "Onde a ocasião, onde a saída?”, pareceu-nos que as Patrícias sentem-se angustiadas e frustradas. Por isso, traduzimos: 
Nossos livros lidos, nossos sonhos findos, era apenas isso?

acentuando, com o martelar dos [i], o tom de desalento e decepção que esse versículo sugere.

4. Estrofe $V l$ - Buscamos manter, o quanto possível, os efeitos sonoros do original:

"Prophéties! prophéties! Lèvres errantes sur les mers, et tout cela qu'enchaîne, sous l'écume, la phrase naissante qu'elles n'achèvent...

"Profecias! profecias! Lábios errantes sobre os mares, e tudo o que é encadeado, sob a espuma, pela frase nascente que eles não acabam...

E mais abaixo, no mesmo canto VI:

... Solitude, ô foison! qui donc pour nous affranchira nos invisibles Sours captives sous l'écume? — Mêlées de ruches et d'ombelles, roueries d'ailes rétives et cent bris d'ailes rabrouées[,]

... Solitude, oh profusão! quem pois para nós aforrará nossas invisíveis Irmãs cativas sob a espuma? - Conflitos de colmeias e de umbelas, ardis de asas arredias e cem fragmentos de asas exprobradas[,]

\section{Estrofe VII}

par les sentiers de ronces où frayent, frémissants,

les vieux flocons d'écume jaunissante,

avec la plume et le duvet des vieilles couvaisons

pelas sendas de sarças onde se estreitam, frementes, os velhos flocos de espuma amarelescente,

com a pluma e a penugem dos velhos chocos

sentiers $=$ sendas

frayent/frémissants $=$ se estreitam $/$ frementes

flocons/couvaisons $=$ flocos $/$ chocos

écume/plume = espuma/pluma

Ronces/fRayent/fRémissants $=\mathrm{saRças/estReitam/fRementes}$

\section{Idem}

et tout l'immense lacis vert,

et toute l'immense vannerie d'or, 
qui vanne, sous les eaux, un age d'ambre et d'or

Levados pelo sentido de lacis (rede de fios entrelaçados) e de vanner (peneirar com o van, peneira), retrabalhamos esta passagem, pondo em lugar de vannerie $($ cestaria $=$ ofício de cesteiro; objetos fabricados pelo cesteiro), joeira (peneira para separar o trigo do joio e de outras sementes com que está misturado) e joeirar (peneirar). E este foi o resultado:

e toda a imensa trama verde, e toda a imensa joeira de ouro, a joeirar, sob as águas, uma idade de âmbar e de ouro

Mantivemos, assim, certos efeitos sonoros:

immENse [ã] | immENse [ã] | AMbre [ã]

imensa $\mid$ imensa $|\operatorname{trAMa}[\tilde{a}]|$ ÂMbar [ã]

veRt $\mid$ vanneRie $\mid$ oR $\mid$ ambRe $\mid$ oR

tRama $\mid$ veRde $\mid$ joeiRa $\mid$ ouRo | joeiRaR | âmbaR | ouRo

E a aliteração VANNErie/VANNE é mantida de outra forma: JOEIRA/JOEIRAr.

\section{Estrofe VIII}

dont la voile a si longtemps longé nos côtes

cuja vela margeou por largo tempo nossas costas

\section{Estrofe IX, 2, 2}

l'homme, sans rivage, près de la femme, riveraine

o homem, sem praias, junto da mulher, praiana

\section{Idem, 4, 1}

plainte de femme et pressurée plainte de femme et non blessée

queixa de mulher e tão premida queixa de mulher e não ferida 


\section{Estrofe IX, 5, 2}

... Celle qui s'épanche à mon épaule gauche et remplit l'anse de mon bras, gerbe odorante et lâche, non liée (et très soyeuse fut l'histoire, a mon toucher, de ces tempes heureuses),

Celle qui se repose sur sa hanche droite, la face close contre moi (et de grands vases ainsi voyagent, sur leur affût d'un bois très tendre et sur leur selle de feutre blanc),

Celle qui s'anime dans le songe contre la montée des ombres (et j'ai tendu le tendelet contre l'embrun de mer et la rosée nocturne, la voile est éventée vers le plus clair des eaux),

Celle-là, plus donce que douceur au coeur de l'homme sans alliance, m'est charge, ô femme, plus légère que chargement d'épices, d'aromates - semence très précieuse et fret incorruptible au vaisseau de mes bras.

que, em português, ficou assim:

... Aquela que se derrama em meu ombro esquerdo e enche a enseada do meu braço, feixe odorante e lasso, não atado (e tão sedosa foi a história, a meu tato, dessas têmporas venturosas),

Aquela que repousa sobre a anca direita, a face cerrada contra mim (e grandes vasos assim viajam, em seu suporte de um lenho muito tenro e em sua sela de feltro branco),

Aquela que se anima no sonho contra o remontar das sombras (e estendi o tendal contra o borrifo do mar e o rocio noturno, a vela é enfunada para o mais claro das águas),

Esta, mais doce que doçura ao coração do homem sem aliança, me é carga, ó mulher, mais leve que carregamento de espécies, de arômatas - semente muito preciosa e frete incorruptível no barco dos meus braços.

Procuramos guardar, o mais possível, o parentesco fônico (rimas etc.):

épanche $\mid$ remplit $\mid$ anse $\mid$ odorante $\mid$ tempes

derrama $\mid$ (ombro) enche $\mid$ enseada | odorante | têmporas

bras/lâche $=$ braço/lasso

liée/toucher $=$ atado/tato

soyeuse/heureuses $=$ sedosa/venturosas

\section{Coro 2}

(nos) lances $\mid$ (nos) milices $\mid$ (cette) lancination $\mid$ (cour) $\mid$ force $\mid$ (exploit)

nossas lanças | nossas milícias | essa lancinação | | coração | (compele) | façanha

12. No canto IX da Estrofe há uma série de verbos no gerúndio, que (1) se distribuem de uma seqüência à outra, (2) têm valor imitativo e (3) desenham um 
movimento de progressão contínua:

IX,5,2

BERÇANT, PRESSANT la masse heureuse de ses frondes

BALANÇANDO, PRESSIONANDO a massa feliz das suas frondes

IX,6,2

PRESSANT, HAUSSANT l'essaim serre des jeunes vagues

PRESSIONANDO, ALÇANDO o enxame cerrado das jovens vagas

Idem

HAUSSANT, ROULANT l'hydre amoureuse de sa force

ALÇANDO, ROLANDO a hidra amorosa da sua força

Nossa atenção, aqui, não foi apenas para as desinências -ando mas para o jogo de sons sibilantes:

$$
\begin{aligned}
& C \zeta \tilde{A} / C ̧ \tilde{A}=\mathrm{ÇA} / \mathrm{SS}-\tilde{\mathrm{A}} \\
& C \zeta \tilde{A} / C ̧ \tilde{A}=\mathrm{SS}-\tilde{\mathrm{A}} / C ̧ \tilde{A} \\
& C \zeta \tilde{A} /(L \tilde{A})=\mathrm{Ç} \tilde{A} /(\mathrm{L} \tilde{A})
\end{aligned}
$$

13. A escolha de uma palavra levou em conta não só um significado legítimo, mas outros elementos, ligados a essa relação som/sentido. Por exemplo, na Estrofe VII, há:

une étincelante et vive dialectique, comme au foyer des grandes émeraudes de famille

uma cintilante e viva dialética, como no foco das grandes esmeraldas de família

A escolha de "cintilante", que pode parecer óbvia, foi o resultado da atenção ao movimento que o brilho das pedras preciosas parece ter. No caso, étincelante e "cintilante" têm a mesma raiz latina scintilla (donde "centelha" e "cintilante"), que na sua forma popular stincilla deu étincelle e étincelante - como que a expedir fagulhas, centelhas. Além disso, a palavra "dialética" vem reforçar a idéia de movimento, sem falar no parentesco sonoro com "cintilante".

14. Outras vezes, optamos por traduzir por outras a mesma palavra que Perse repete em situações diversas. Por exemplo: bois foi traduzida ora por "lenho", ora por "madeira" e até mesmo por "pau", porque o contexto pedia. 
Em Invocação 6,

ses Magiciennes trépignant sur leurs socques de bois

suas Magas sapateando nos seus socos de pau.

Tomamos esse monossílabo pela sua força expressiva e por reforçar a idéia dada pelo verbo "sapatear" (trépigner), além de mimar o barulho dos "socos" batendo no chão.

E, por fim, uma palavra sobre o vocabulário. Roger Caillois (1972: 17) chama a atenção para o léxico persiano, que pode dar ao seu leitor a impressão de rebuscamento e até mesmo de preciosismo: “[O vocabulário de Saint-John Perse] ganhou vocábulos muito raros e muito concretos, que quase não se ouvia e que parecem triados sem motivo pelo poeta". São palavras ligadas a ofícios e profissões, ou tiradas o mais das vezes da experiência, antes que da cultura, empregadas, porém, no devido momento e lugar. O simples recurso ao dicionário nem sempre resolve os problemas ligados ao significado desses e de outros termos, pois, dado o contexto, eles adquirem novo sentido, diferente ou mais denso; ou ali estão porque sua etimologia levará o leitor a remontar às suas raízes, para a descoberta de significados insuspeitados, que se desgastaram ou se perderam com o tempo.

A fidelidade ao vocabulário persiano é um dos pontos cruciais da tradução da sua poesia, porque nem sempre se encontra um correspondente em português que satisfaça as exigências do texto poético, ou se coadune com o contexto em que ele se situa. Mas fidelidade, em tradução, não é sinônimo de servilidade. 


\section{Referências bibliográficas}

CAILLOIS, Roger (1972) Poétique de Saint-John Perse: Paris, Gallimard.

DELBROUILLE, Paul (1961) Poésie et sonorités. Paris: Belles-Lettres.

ELBAZ, Shlomo (1977) Lectures d'Anabase de Saint-John Perse. Le desert, le désir. Genève: Éditions l'Âge d'Homme.

FREDERIC, Madeleine (1978) "La Répétition dans Amers de Saint-John Perse. Quelques aspects de son rôle imitative”. Cahiers Saint-John Perse, vol. 1, pp. 123-136.

LEVILLAIN, Henriette (1987) Sur deux versants. La creation chez Saint-John Perse d'après les versions anglaises de son œuvre poétique. Paris: Gallimard.

PAZ, Octavio (1956) El arco y la lira. México: Fondo de Cultura Econômica. PERSE, SAINT-JOHN (1994) Euvres complètes. Paris: Gallimard. 